\title{
FGFIO/FGFR2 signal induces cell migration and invasion in pancreatic cancer
}

\author{
S Nomura', H Yoshitomi*,', S Takano', T Shida', S Kobayashi', M Ohtsuka', F Kimura', H Shimizu', \\ H Yoshidome', A Kato' and M Miyazaki' \\ 'The Department of General Surgery, Graduate School of Medicine, Chiba University, I-8-I Inohana, Chuo-ku, Chiba city, Chiba 260-8670, Japan
}

\begin{abstract}
Pancreatic cancer has one of the highest mortalities among all malignancies and there is an urgent need for new therapy. This might be achieved by resolving the detailed biological mechanism, and in this study we examined how pancreatic cancer cells develop aggressive properties by focusing on signalling through the fibroblast growth factor (FGF) I 0 and FGF receptor (FGFR)2, which play important roles in pancreatic organogenesis. Immunostaining of pancreatic cancer tissues showed that FGFR2 was expressed in cancer cells, whereas FGFIO was expressed in stromal cells surrounding the cancer cells. Patients with high FGFR2 expression in cancer cells had a shorter survival time compared to those with low FGFR2 expression. Fibroblast growth factor 10 induced cell migration and invasion of CFPAC-I and AsPC-I pancreatic cancer cells through interaction with FGFR2-IIlb, a specific isoform of FGFR2. Fibroblast growth factor 10 also induced expression of mRNA for membrane type I-matrix metalloproteinase (MTI-MMP) and transforming growth factor (TGF)- $\beta$ I, and increased secretion of TGF- $\beta$ I protein from these cell lines. These data indicate that stromal FGFIO induces migration and invasion in pancreatic cancer cells through interaction with FGFR2, resulting in a poor prognosis. This suggests that FGFI0/FGFR2 signalling is a promising target for new molecular therapy against pancreatic cancer. British Journal of Cancer (2008) 99, 305-313. doi: I 0. I038/sj.bjc.6604473 www.bjcancer.com

Published online I July 2008

(c) 2008 Cancer Research UK
\end{abstract}

Keywords: pancreatic cancer; fibroblast growth factor 10; fibroblast growth factor receptor 2; cancer stromal cell

Pancreatic cancer has one of the highest mortalities among all malignancies, and is the fourth most common cause of cancer death in the United States and the fifth in Japan (Li et al, 2004; Willett et al, 2005). Although significant advances are now being made into the management of the disease, the 5-year survival rate still remains poor (Willett et al, 2005; Ghaneh et al, 2007). Therefore, there is an urgent need for new therapies for pancreatic cancer, based on an improved understanding of the molecular biology of the disease. The high mortality rate of pancreatic cancer is, in part, owing to difficulties of early diagnosis, the high incidence of metastatic disease at the time of diagnosis, and rapid progression of the disease. In addition, although newer adjuvant modalities are greatly increasing the prognosis (Ghaneh et al, 2008), most patients who undergo the surgery eventually relapse and die of the disease, even with curative resection (Li et al, 2004; Willett et al, 2005).

An understanding of the mechanisms underlying the biological aggressiveness of pancreatic cancer may be key for development of new therapies. Therefore, in this study we examined the molecular mechanisms underlying cellular invasion and metastasis of pancreatic cancer cells. Cellular and genetic studies have shown that tumour growth is not determined by malignant cancer cells alone, but also by cells in the tumour stroma. Supply of oxygen and nutrients by endothelial cells of blood vessels are critical for maintenance of the tumour microenvironment, and stromal

*Correspondence: Dr H Yoshitomi; E-mail: yoshitomi@faculty.chiba-u.jp Revised 7 May 2008; accepted 20 May 2008; published online I July 2008 fibroblasts are the principal source of extracellular matrix, which serves as a scaffold for cancer cells (Kalluri and Zeisberg, 2006). In addition, recent studies have revealed more active roles of stromal cells in tumour initiation and progression through direct interaction with tumour cells. For example, stromal cell-derived factor-1 (SDF-1/CXCL12) released from fibroblasts promotes cancer cell proliferation through a specific receptor, CXCR4, in several types of malignancies, including breast cancer (Orimo et al, 2005) and pancreatic cancer (Koshiba et al, 2000; Marchesi et al, 2004). Immune cells also play important roles in cancer progression (Pollard, 2004); for example, tumour-associated macrophages induced by colony-stimulating factor 1 promote invasiveness of cancer cells (Lin et al, 2001). Given this background, we hypothesized that stromal cell-cancer cell interactions have an important role in acquisition of the aggressive character by pancreatic cancer, and we examined signalling molecules that may be associated with this mechanism.

The molecular mechanisms underlying carcinogenesis are often similar to those in organogenesis. Interactions between stromal and parenchymal cells are important during organ development, and signals from stromal cells regulate epithelial cell growth and differentiation in pancreatic development. The classical tissue recombinant study by Golosow and Grostein (1962) showed that growth and morphogenesis of the developing pancreas depend on mesenchymal interactions, and more recently advances in molecular biology have allowed the molecular basis of this interaction to be established. We have shown that signals from endothelial cells and mesenchymal cells surrounding the 
pancreatic bud are crucial for initiation of pancreatic development from endoderm (Yoshitomi and Zaret, 2003; Jacquemin et al, 2006). Especially, we found that fibroblast growth factor-10 (FGF10) from mesenchymal cells maintained expression of Ptf1a, a critical transcription factor for initiation of pancreatic development, in pancreatic progenitor cells (Jacquemin et al, 2006). Mice deficient in FGF10 or the FGF receptor-2 (FGFR2)/IIIb isoform, the specific receptor for FGF10 (Igarashi et al, 1998), show impaired pancreatic development (Bhushan et al, 2001; Pulkkinen et al, 2003). However, it is unknown if FGF10/FGFR2-IIIb-signalling is associated with carcinogenesis in pancreatic cancer. In this study, we show that FGF10/FGFR2-signalling has an important role in pancreatic cancer progression, and we suggest that these results may lead to a new therapy and a better prognosis for patients with pancreatic cancer.

\section{MATERIALS AND METHODS}

\section{Patients and tissue samples}

Pancreatic cancer tissues were obtained from 76 pancreatic cancer patients who underwent curative surgical resection in the Department of General Surgery, Chiba University Hospital, Chiba, Japan, from June 2001 to April 2006. All patients were diagnosed histologically as primary invasive pancreatic ductal carcinoma. The patient characteristics are summarised in Table 1 . The study protocol was approved by the Ethics Committee of our institute and written informed consent was obtained from all patients.

\section{Immunohistochemistry}

Paraffin-embedded tissues were cut into $4 \mu \mathrm{m}$ serial sections and deparaffinised. The sections were placed in citrate buffer $\left(10 \mathrm{mmoll}^{-1} \mathrm{pH} 6.0\right)$ with $0.2 \%$ Tween 20 and boiled in a microwave oven (two times $\times 6 \mathrm{~min}$ ) to retrieve the antigen. They were then rinsed and blocked in $10 \% \mathrm{H}_{2} \mathrm{O}_{2}$ solution with methanol for $10 \mathrm{~min}$. Next, the sections were incubated with goat anti-human FGF10 polyclonal antibody (R\&D Systems, Minneapolis, MN, USA) at $1: 20$ dilution, mouse anti-human FGFR2 monoclonal antibody (R\&D Systems) at $1: 10$ dilution, or rabbit anti-human CD3 monoclonal antibody (ready-to-use without dilution) (Thermo Fisher Scientific Anatomical Pathology, Fremont, CA, USA) overnight at $4^{\circ} \mathrm{C}$. They were then rinsed in PBS and incubated for $60 \mathrm{~min}$ with a secondary antibody labelled with streptoavidin-biotin-peroxidase for goat polyclonal antibody (DAKO LSAB $+{ }^{\mathrm{TM}}$ System, DAKO, Glostrup, Denmark), or dextran polymer-peroxidase for mouse monoclonal antibody (DAKO EnVision $^{\mathrm{TM}}$ System, DAKO). For detection of anti-CD3 antibody, CSA II biotin-free catalysed amplification system with rabbit link (DAKO) was used. The bound complex was visualised using diaminobenzidine liquid chromogen (Dako) and counterstained with haematoxylin. Goat polyclonal IgG (Santa Cruz Biotechnology. Santa Cruz, CA, USA) at an optimal dilution was used as a negative control.

\section{Cell lines and culture conditions}

AsPC-1 cells were maintained in RPMI-1640 medium (Invitrogen, Carlsbad, CA, USA) and MIA PaCa-2, PANC-1 and CFPAC-1 cells

Table I Characteristics of pancreatic cancer patients in $I H C$ analysis

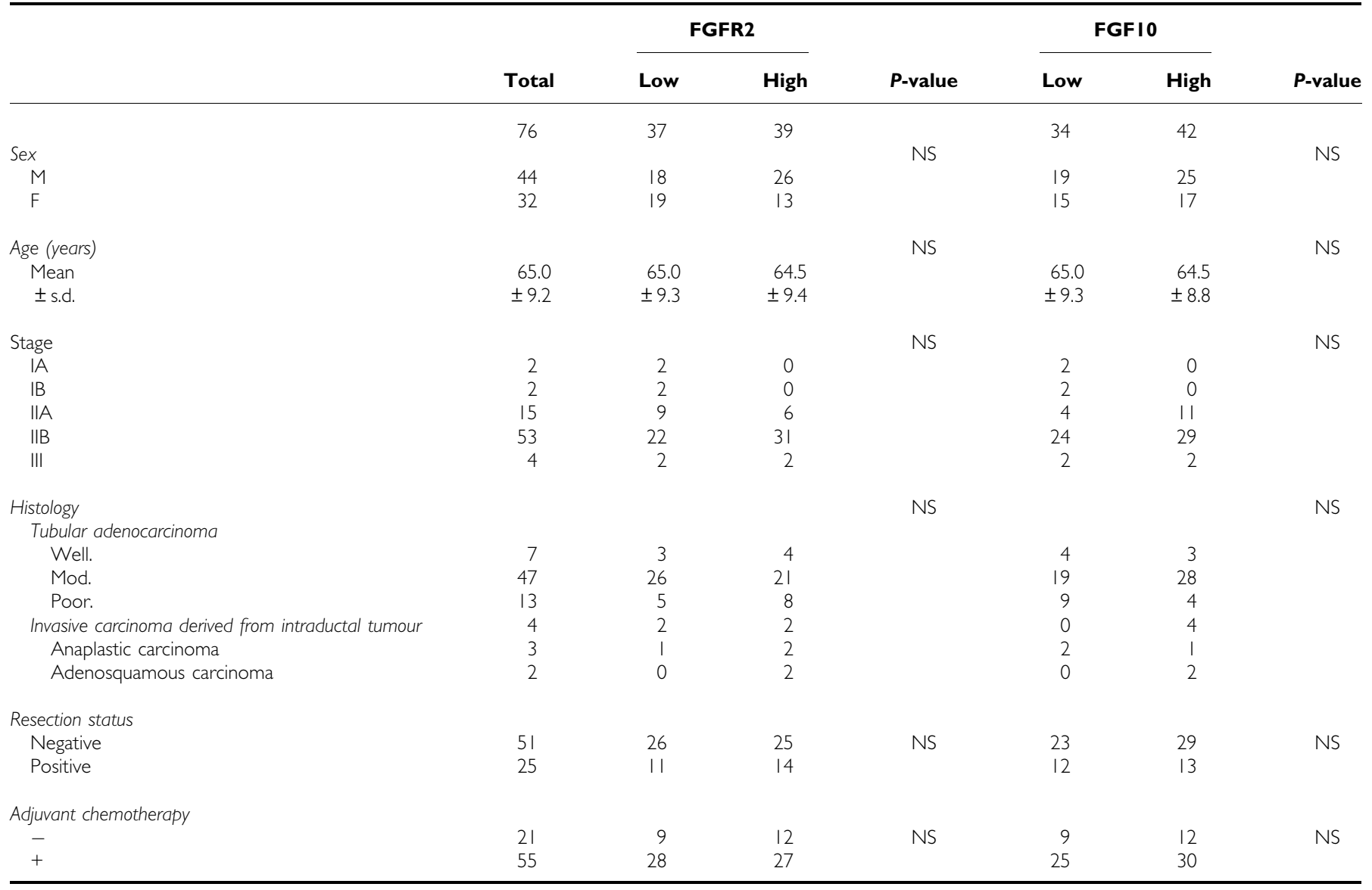

Mod = moderately differentiated; NS = no significant; Poor = poorly differentiated; s.d. = standard deviation; Well = well differentiated. Patient stage was determined according to UICC TNM classification. 
were cultured with DMEM medium (Sigma-Aldrich, St Louis, MO, USA). All cell lines were incubated in a humidified atmosphere containing $5 \% \mathrm{CO}_{2}$ at $37^{\circ} \mathrm{C}$. Each medium contained $10 \%$ fetal bovine serum (Invitrogen), $100 \mathrm{U} \mathrm{ml}^{-1}$ penicillin and $0.1 \mathrm{mg} \mathrm{ml}^{-1}$ streptomycin sulphate (Sigma-Aldrich).

For some experiments, cells were seeded $\left(1 \times 10^{6}\right.$ cells in $2 \mathrm{ml}$ medium per well) in 6-well plates, and cultured for $24 \mathrm{~h}$. Then cells were cultured with serum-free medium for another $24 \mathrm{~h}$ and changed to new serum-free medium with recombinant human FGF10 (R\&D systems) or/and FGFR2-IIIb/IgG Fc Chimera (R\&D systems) for indicated time in each experiments. Cells and medium were harvested for further experiments.

Transforming growth factor $\beta 1$ (TGF- $\beta 1$ ) concentration was measured using Quantikine Human TGF- $\beta 1$ immunoassay kit (R\&D systems).

\section{Reverse transcription - PCR}

Total RNA was extracted from cultured cells, pancreatic cancer tissues and adjacent normal tissues with an RNeasy Mini Kit (QIAGEN GmbH, Hilden, Germany), according to the manufacturer's instructions. cDNA was synthesised from $1 \mu \mathrm{g}$ of total RNA with SuperScript ${ }^{\mathrm{TM}}$ III First-Strand Synthesis SuperMix for reverse transcription (RT) - PCR (Invitrogen). Polymerase chain reaction was performed with the following primer sets: FGF10, forward 5-ACATTGTGCCTCAGCCTTTC-3, reverse 5-CCCCTTCTTGTT CATGGCTA-3; FGFR2-IIIb, forward 5-TATATAGGGCAGGCAAC CA-3, reverse 5-GCTGAAGTCTGGCTTCTTGG-3; FGFR2-IIIc, forward 5-GTGCTTGGCGGGTAATTCTA-3, reverse 5-GCTGAAGTCT GGCTTCTTGG-3; and glyceraldehyde-3-phosphate dehydrogenase (GAPDH), forward 5-GTCAGCCGCATCTTCTTTTG-3, reverse 5-TTCACACCCATGACGAACAT-3. The RT-PCR conditions for FGF10, FGFR2-IIIb, FGFR2-IIIc and GAPDH were as follows: $94^{\circ} \mathrm{C}$ for $2 \mathrm{~min}, 40 \mathrm{cycles}$ at $94^{\circ} \mathrm{C}$ for $15 \mathrm{~s}, 58^{\circ} \mathrm{C}$ for $30 \mathrm{~s}$, and $72^{\circ} \mathrm{C}$ for $30 \mathrm{~s}$, with an extension step of $7 \mathrm{~min}$ at $72^{\circ} \mathrm{C}$ at the end of the last cycle.

\section{Quantitative RT - PCR}

Quantitative RT-PCR was performed as described previously (Mitsuhashi et al, 2003). Primers for 18 genes related to cancer invasion and motility have been described by Ide et al (2006). The mRNA levels of these genes (E-Cadherin, N-Cadherin, Snail, MMP-1, MMP-2, MMP-7, MMP-9, MT1-MMP, TIMP-2, uPA, TGF- $\beta 1$, HGF, c-Met, RhoA, CD44, Integrin- $\alpha 4$, Integrin- $\beta 4$, and VEGF-A) were determined as the absolute number of copies normalised against the GAPDH mRNA copy number (Mitsuhashi et al, 2003). These experiments were performed three times independently.

\section{Cell migration assay}

A migration assay was performed in 12-well plates using a Quantitative Cell Migration ${ }^{\mathrm{TM}}$ Assay Kit (Chemicon International, Temecula, CA, USA) with an $8.0 \mu \mathrm{m}$ pore size collagen-coated chamber membrane. The cells were seeded $\left(1 \times 10^{5}\right.$ cells in $0.3 \mathrm{ml}$ of serum-free medium) in the upper chamber and cultured for $24 \mathrm{~h}$ for attachment. The medium was then replaced by fresh serumfree medium for another $24 \mathrm{~h}$, before addition of recombinant human FGF10 (100 $\mathrm{ng} \mathrm{ml}^{-1}$ ) (R\&D Systems) to the lower chamber. In some experiments, recombinant human FGFR2-IIIb/IgG Fc Chimera $\left(500 \mathrm{ng} \mathrm{ml}^{-1}\right.$ ) (R\&D Systems) was also added to the lower chamber. The cells were incubated for $12 \mathrm{~h}$ and the number of cells that passed through the membrane was counted according to the manufacturer's instructions. All experiments were performed in triplicate and independently at least three times.

\section{Cell invasion assay}

An invasion assay was performed in 24-well plates using a BD Biocoat $^{\mathrm{TM}}$ Matrigel $^{\mathrm{TM}}$ Invasion Chamber (BD Biosciences, Bedford, MA, USA) with an $8.0 \mu \mathrm{m}$. pore size polyethylene terephthalate (PET) membrane coated with Matrigel. The inserts were rehydrated by adding $0.5 \mathrm{ml}$ of warm culture medium at $37^{\circ} \mathrm{C}$ for $2 \mathrm{~h}$. The cells were seeded $\left(5 \times 10^{5}\right.$ cells in $0.5 \mathrm{ml}$ of serum-free medium) in the upper chamber and cultured as described in the method for the migration assay. The number of seeded cells, culture conditions and other items were also similar to those for the migration assay. The cells were incubated for $24 \mathrm{~h}$ and the number of cells that passed through the membrane was counted according to the manufacturer's instructions. All experiments were performed in triplicate and independently at least three times.

\section{Statistical analysis}

Values are expressed as means \pm s.d. The distribution of categorical data for FGFR2 immunostaining in tissue samples and for clinicopathological characteristics were assessed by a $\chi^{2}$ test and a Fisher's exact test. Survival time was calculated using the KaplanMeier method and compared by log-rank test. Cell migration and cell invasion data were analysed using a Student's $t$-test and a Mann-Whitney $U$-test. Statistical significance was assumed for $P<0.05$.

\section{RESULTS}

Expression of FGFR2 in pancreatic cancer cells and FGF10 in cancer stromal cells

To examine the expression pattern of FGFR2 and FGF10 in pancreatic cancer tissues, we performed immunohistochemical staining of 76 tissue samples of invasive pancreatic ductal carcinoma and of normal pancreatic tissues. FGF receptor-2 immunoreactivity was weak to moderate in pancreatic ductal cells in normal tissues (Figure 1A; arrow) and acinar cells (Figure 1A; arrowhead), as well as in islet cells (data not shown), as described previously (Ishiwata et al, 2002). On the other hand, immunostaining of FGF10 did not occur in normal pancreatic tissue, as also described previously (Ishiwata et al, 2002) (Figure 1B).

In pancreatic cancer tissues, cancer cells expressed FGFR2 at various levels (Figure 1C), but did not express FGF10 (Figure 1D). Pancreatic cancer tissue often contains a few islet cells (Figure $1 \mathrm{E}$ and 1F; arrowheads) and we compared the expression levels of FGFR2 in cancer cells and islets. In 39 cases (51.3\%), FGFR2 immunoreactivity in cancer cells was stronger than in islets (high expression group, Figure 1E). In the other 37 cases (48.7\%), FGFR2 immunoreactivity was not found or was faint in cancer cells, and was weaker than in normal islet cells (low expression group, Figure 1F). There was no correlation between FGFR2 immunoreactivity levels and tumour histological findings (Table 1).

Pancreatic cancer cells did not express FGF10 in any samples (Figure 1D), but scattered cells in stroma surrounding the cancer cells showed strong expression of FGF10 (Figure 1D; arrows). Fibroblast growth factor 10-positive stromal cells in cancer tissues were found in 42 cases (55.3\%), and interestingly, were mainly localised close to cancer cells (Figure 1D and 1E). Moreover, of the 42 cancer tissue samples with FGF10-positive stromal cells, 29 (69.0\%) showed high FGFR2 expression in cancer cells, and there was a significant correlation between the presence of FGF10positive stromal cells and high FGFR2 expression in cancer cells $(P=0.013)$.

Next we examined which kind of cancer stromal cells expressed FGF10. We stained sequential sections with antibody against FGF10 and stromal cell markers (CD68; macrophage marker, $\alpha$-smooth muscle actin; activated fibroblast marker, CD3; T-cell 
FGFR2
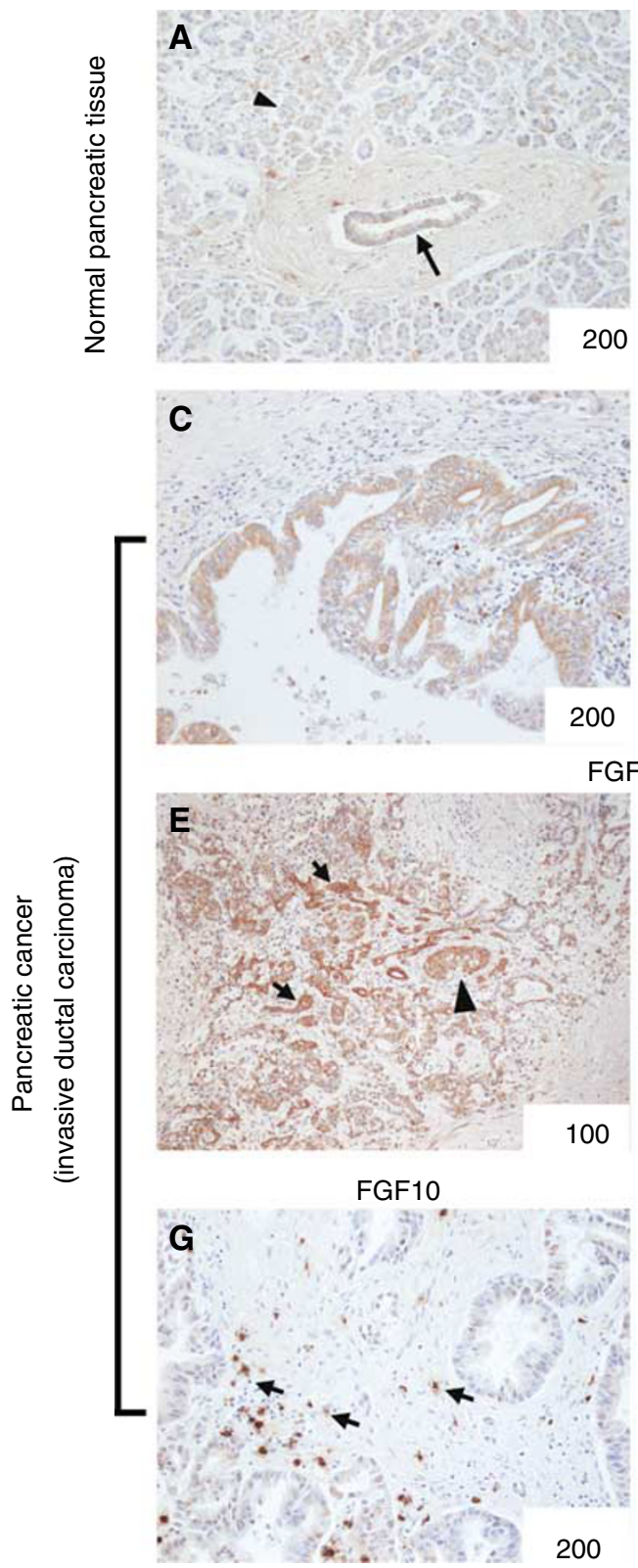

FGF10
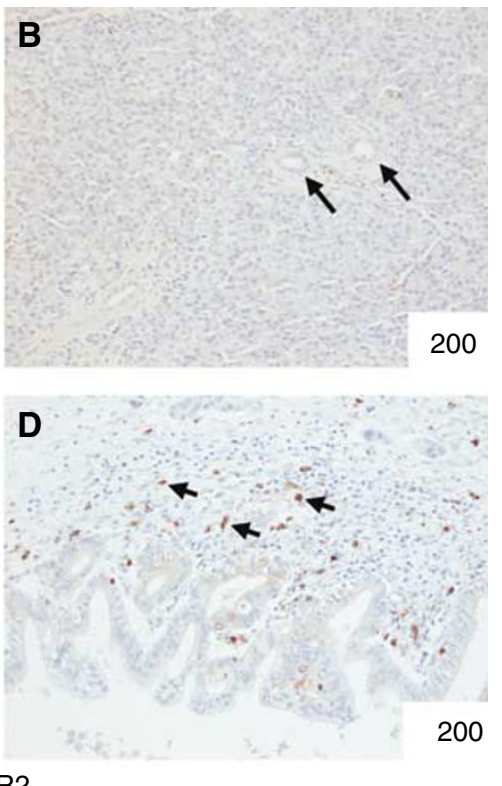

GFR2
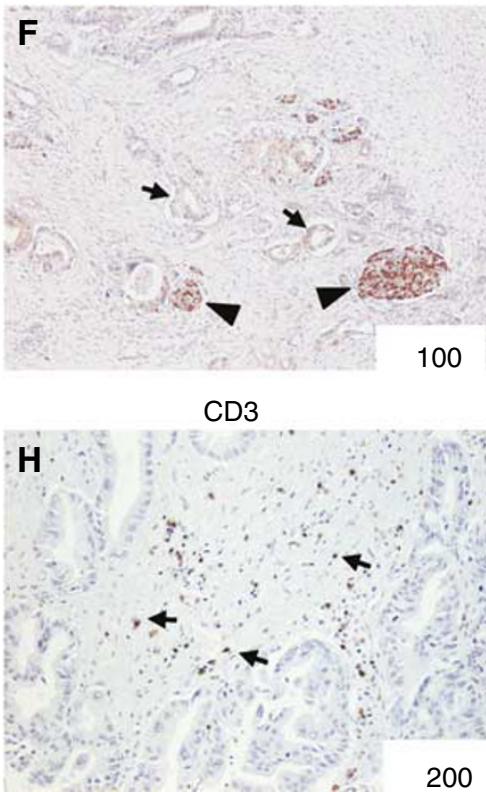

Figure I Expression patterns of FGFR2 and FGFIO in normal pancreas and pancreatic cancer. The magnification is shown in the right bottom corner of each figure. (A and B) Immunostaining of FGFR2 (A) and FGFIO (B) in normal pancreas, showing that FGFR2 is expressed weakly in ductal cells $(\mathbf{A}$, arrow) and acinar cells (A, arrow head), and that no obvious FGFIO staining is found in normal pancreatic tissue, including ductal cells (B, arrows). (C and $\mathbf{D}$ ) Immunostaining of FGFR2 $(\mathbf{C})$ and FGFIO (D) in pancreatic cancer tissues, showing that FGFR2 is expressed in cancer cells $(\mathbf{C})$, whereas FGFIO is expressed in scattered cells in the stroma surrounding cancer cells (D, arrows). (E and $\mathbf{F}$ ) Immunostaining of FGFR2 in pancreatic cancer cells. (E) Representative result from the FGFR2 high expression group, indicating higher FGFR2 expression in cancer cells (arrows) compared with islets (arrow head). (F) Representative result from the FGFR2 low expression group, showing lower FGFR2 expression in cancer cells (arrows) compared with islet (arrow heads). (G and $\mathbf{H}$ ) Immunostaining of FGFIO $(\mathbf{G})$ and CD3 $(\mathbf{H})$, marker for T cell. Fibroblast growth factor 10 and CD3 are both expressed in scattered cells with similar cell shape in the stroma surrounding cancer cells (arrows).

marker). Within them, CD3-positive stromal cells, T-cells, were located similar to FGF10-positive stromal cells and also has similar cell shapes (Figure $1 \mathrm{G}$ and $1 \mathrm{H}$; arrows). However, due to the technical difficulties, we could not demonstrate that FGF10expressing cells were identical with T-cells.

Overall, the results show that FGFR2 is expressed in pancreatic cancer tissue, and that its ligand, FGF10, is expressed in stromal cells.

\section{FGFR2 expression levels correlates with prognosis of pancreatic cancer patients}

Next, we examined whether strong expression of FGFR2 in cancer cells correlated with patient prognosis. The 76 patients were divided into two groups according to the expression level of FGFR2 in cancer cells (the high and low expression groups in Table 1). The expression level of FGFR2 was not correlated with 


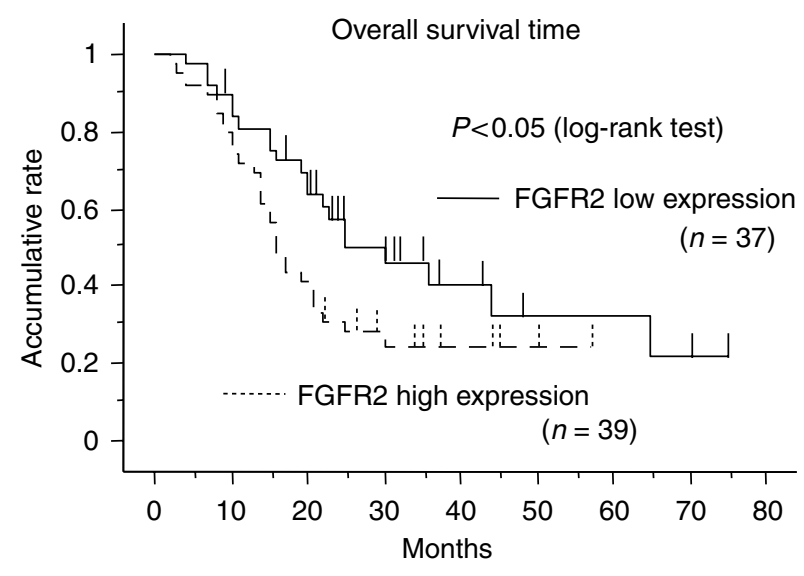

Figure 2 Kaplan-Meier survival curves for patients with high and low FGFR2 expression. Patients with low FGFR2 expression had a significantly longer overall survival time compared to those with high FGFR2 expression $(P<0.05$ by log-rank test).

clinicopathological factors such as sex, age and pathological stage (Table 1). There were no statistical differences in the resection status of both groups. Also, the ratios of patients who received adjuvant chemotherapy (using gemcitabine) were similar in both groups, indicating that patients in both groups were treated with similar therapeutic approaches after surgery (Table 1). Interestingly, Kaplan-Meier analysis showed that patients with high FGFR2 expression had a significantly shorter overall survival time compared to those with low expression levels (Figure 2) $(P=0.047$ by log-rank test). Moreover, patients with high FGFR2 expression had significantly more nodal invasion, a larger tumour size, and a worse UICC Stage (Table 2; $P=0.0263, P=0.0469$, and $P=0.022$, respectively, by $\chi^{2}$-test). There was no significant correlation between survival time and the presence of FGF10 in stromal cells in cancer tissue (data not shown).

\section{FGF10/FGFR2-IIIb signalling induces cell migration and invasion}

The expression pattern of FGF10 and FGFR2 in cancerous tissue and the poor prognosis of patients with high FGFR2 expression in cancer cells indicate that a stromal cell-epithelial cell interaction through FGF10/FGFR2 signalling might induce the malignant properties of pancreatic cancer. To examine this hypothesis, we analysed the effects of FGF10 on the proliferation, invasion and migration of pancreatic cancer cells. For this purpose, four pancreatic cancer cell lines were used: MIA PaCa-2, PANC-1, CFPAC-1 and AsPC-1 cells.

First, we examined whether these cell lines expressed FGFR2 and FGF10. Reverse transcriptase-PCR analysis showed that all four cell lines did not express FGF10 mRNA, consistent with the results of immunostaining showing FGF10 expression in stromal cells, but not in cancer cells, in pancreatic cancer tissue (Figure 3A). Fibroblast growth factor 10 activity is dependent on its binding to the FGFR2-specific isoform, FGFR2-IIIb (Igarashi et al, 1998). Therefore, a primer set for FGFR2-IIIb was designed with a 5 primer for its specific exon in the FGFR2 gene. Reverse transcriptase-PCR analysis with this primer showed that CFPAC-1 and AsPC-1 cells expressed the FGFR2-IIIb isoform, whereas the other two cell lines did not do so (Figure $3 \mathrm{~A}$ ).

To examine cancer cell proliferation, the cells were stimulated with various concentrations of FGF10 $\left(10-200 \mathrm{ng} \mathrm{ml}^{-1}\right)$, but no effect of FGF10 was observed in any of the four cell lines (data not shown). Next, we examined whether FGF10 affects migration or invasion of pancreatic cancer cells. Representative results from the cell migration and invasion assays are shown in Figure $3 \mathrm{~B}$.
Table 2 Clinico-pathological features of pancreatic cancer patients in FGFR2-IHC analysis

\begin{tabular}{|c|c|c|c|c|}
\hline & \multirow[b]{2}{*}{$\begin{array}{c}\text { Total } \\
76\end{array}$} & \multicolumn{2}{|c|}{ FGFR2 expression of IHC } & \multirow[b]{2}{*}{$P$-value } \\
\hline & & $\begin{array}{c}\text { Low expression } \\
37\end{array}$ & $\begin{array}{c}\text { High expression } \\
39\end{array}$ & \\
\hline $\mathrm{T}(1,2,3 / 4)$ & $42 / 34$ & $23 / 14$ & $19 / 20$ & NS \\
\hline$N(0 / 1,2,3)$ & $20 / 56$ & $14 / 23$ & $6 / 33$ & 0.0263 \\
\hline$M(0 / 1)$ & $67 / 9$ & $35 / 2$ & $32 / 7$ & NS \\
\hline ly $(0 / 1,2,3)$ & $14 / 62$ & $9 / 28$ & $5 / 34$ & NS \\
\hline$\vee(0 / 1,2,3)$ & $31 / 45$ & $19 / 18$ & $12 / 27$ & NS \\
\hline ne $(0 / 1,2,3)$ & $1 \mid / 65$ & $7 / 30$ & $4 / 35$ & NS \\
\hline Size $(</ \geqslant: 30 \mathrm{~mm})$ & $37 / 39$ & $23 / 14$ & $14 / 25$ & 0.022 \\
\hline$|\mathrm{A},| \mathrm{B},\|\mathrm{A} /\| \mathrm{B}, \|||$ & $19 / 57$ & $13 / 24$ & $6 / 33$ & 0.0469 \\
\hline Poor/others & $13 / 63$ & $8 / 29$ & $5 / 34$ & NS \\
\hline
\end{tabular}

ly = lymphatic invasion; $M=$ distant metastasis; $N=$ nodal metastasis; ne = neural invasion; NS = no significant; Poor=poorly differentiated adenocarcinama; $T=$ tumour depth; $v=$ venous invasion. Patient stage was determined according to UICC TNM classification.

Interestingly, FGF10 stimulated cell migration and invasion of cells that expressed FGFR2-IIIb (CFPAC-1 and AsPC-1), but not of cells without expression of the specific receptor (MIA PaCa-2 and PANC-1) (Figure 3C and 3D). For CFPAC-1 cells, migration was almost doubled (Figure 3C) and invasion was increased by 1.5 times (Figure 3D) following stimulation with FGF10 $\left(100 \mathrm{ng} \mathrm{ml}^{-1}\right)$. Similar results were obtained for AsPC-1 cells (Figure 3C and 3D).

To confirm that the effects of FGF10 on pancreatic cells were mediated through FGFR2-IIIb, we used a molecular hybrid including the FGFR2-IIIb extracellular domain and the carboxyterminal Fc region of human IgG (recombinant human FGFR2IIIb/IgG Fc Chimera). Such hybrids inhibit signalling through the FGFR2-IIIb receptor by antagonising ligand binding (Jung et al, 1999). Stimulated migration of CFPAC-1 cells by $100 \mathrm{ng} \mathrm{ml}^{-1}$ FGF10 was completely inhibited by addition of FGFR2-IIIb/IgG Fc Chimera $\left(500 \mathrm{ng} \mathrm{ml}^{-1}\right.$ ) (Figure 3E; compare the second and third columns). The effects of the chimera were due to inhibition of signalling through FGFR2-IIIb, rather than to a direct effect of the chimera on the cells, as addition of chimera alone did not affect cell migration (Figure 3E; compare the first and fourth columns). Invasion of CFPAC-1 cells stimulated by FGF10 was also inhibited by FGFR2-IIIb/IgG Fc Chimera (Figure 3F). Overall, these results indicate that FGF10 stimulates migration and invasion of cancer cells through its specific receptor, FGFR2-IIIb.

\section{Upregulation of MT1-MMP and TGF- $\beta 1$ mRNA by FGF10}

To examine the molecular mechanisms through which FGF10 signalling induces migration and invasion of pancreatic cancer cells with FGFR2-IIIb expression, we analysed whether FGF10 stimulation induced mRNA expression of 18 genes related to cell mobility in CFPAC-1 cells (see Materials and methods for the 18 genes). CFPAC-1 cells were cultured with recombinant human FGF10 $\left(100 \mathrm{ng} \mathrm{ml}^{-1}\right)$ for 12,24 and $48 \mathrm{~h}$, and then total RNA were extracted and the mRNA levels of the 18 genes were analysed by quantitative RT-PCR. Among these genes, FGF10 upregulated the expression levels of MT1-MMP (Figure 4A) and TGF- $\beta 1$ (Figure 4B) mRNAs in a time-dependent manner. In CFPAC-1 cells, the mRNA expression levels for both genes were almost 10 times higher after FGF10 stimulation for $48 \mathrm{~h}$ compared with the level before stimulation. The concentration of TGF- $\beta 1$ in culture medium was also upregulated in time-dependent manner in CFPAC-1 cells (Figure 4C) and also in AsPC-1 cells (data not shown). The secretion of TGF- $\beta 1$ by FGF10 stimulation in CFPAC-1 cells was inhibited by FGFR2-IIIb/IgG chimera (Figure 4D), indicating FGF10-induced TGF- $\beta 1$ secretion through FGFR2. 
A

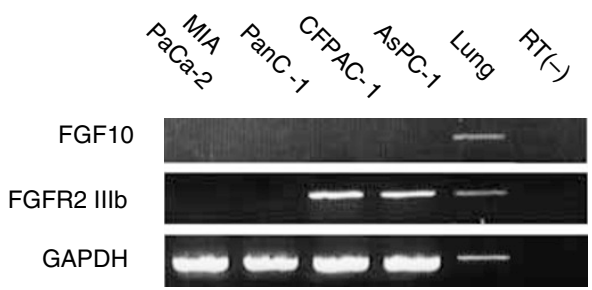

C

FGF10 - cell migration assay

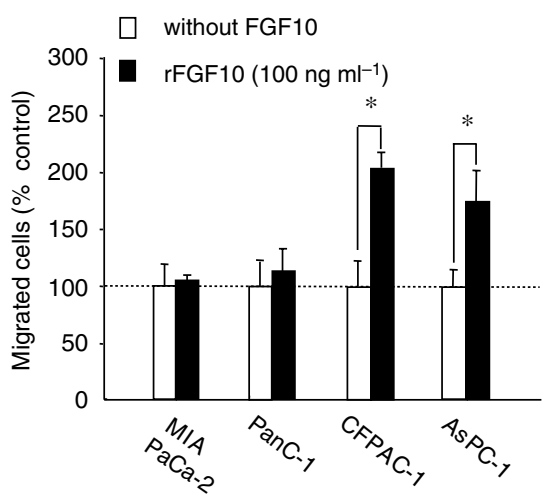

E

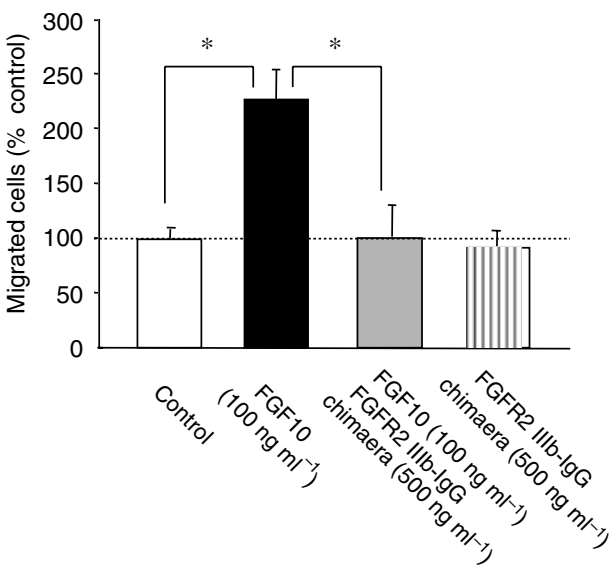

B

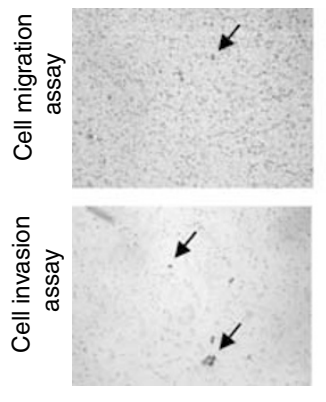

FGF10 (-)
CFPAC-1

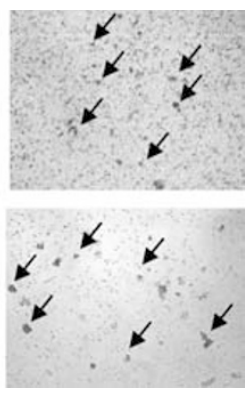

FGF10 (+)

D FGF10 - cell invasion assay

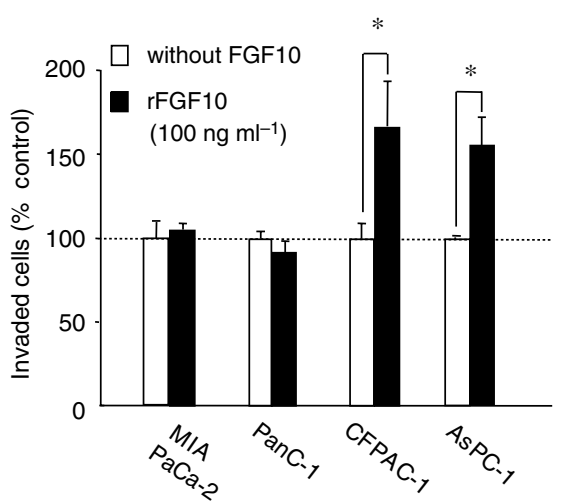

F FGF10 - cell invasion assay

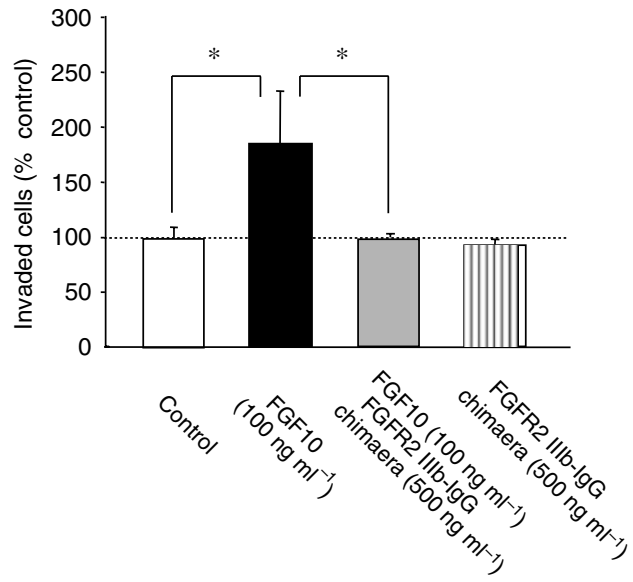

Figure 3 Fibroblast growth factor 10 induces cell migration and invasion in pancreatic cell lines with FGFR2-IIlb expression. (A) RT-PCR analysis of FGFIO and FGFR2-IIIb in four pancreatic cell lines and CDNA obtained from normal lung tissue as a positive control. None of the cell lines express FGFI0. MIA PaCa-2 and PanC-I cells do not express FGFR2-IIIb, but CFPAC-I and AsPC-I do express this gene. (B) Representative results of cell migration (upper panels) and invasion (lower panels) for CFPAC-I cells. Representative migrated and invaded cells are indicated with arrows. (C and D) Cell migration (C) and invasion (D) assay of all four cell lines cultured without (white column) or with (black column) FGFI0 (I00 ng ml ${ }^{-1}$ ). FGF I0-induced cell migration and invasion in CFPAC-I and AsPC-I cells, but not in MIAPaCa-2 and PanC-I cells. The numbers of migrated or invaded cells cultured with FGFI0 are shown relative to a value of $100 \%$ for cell migration without ligand. (E and $\mathbf{F}$ ) Inhibition of FGFR2-IIlb signalling by an FGFR2-IIIb/lgG chimera in CFPAC-I cells. Migration $(\mathbf{E})$ and invasion $(\mathbf{F})$ assay. The numbers of migrated or invaded cells are shown relative to a value of I00\% for cells cultured without FGFIO or chimera (control; white column). FGFI0-induced migration and invasion in CFPAC-I cells (black column). Addition of the FGFR2-IIlb/lgG chimera completely eliminated the effects of FGFIO (grey column), whereas the chimera itself did not affect cell migration and invasion of CFPAC-I cells (striped column). $* P<0.05$.

\section{DISCUSSION}

In this study, we investigated the molecular mechanisms underlying the aggressiveness of pancreatic cancer, and found that FGF10/FGFR2-IIIb-signalling plays an important role in inducing migration and invasion of pancreatic cancer cells. FGF receptor-2-
IIIb is a splice variant of FGFR2 that is predominantly expressed by cells of epithelial origin and is involved in proliferation of these cells, whereas other FGFR2 variant transcripts are detected in mesenchymal cells (Miki et al, 1992). Ishiwata et al (1998) first showed that the FGFR2-IIIb isoform of the FGF receptor is expressed in pancreatic cancer cells. We confirmed this result by 
CFPAC-1

A

$$
\text { A }
$$

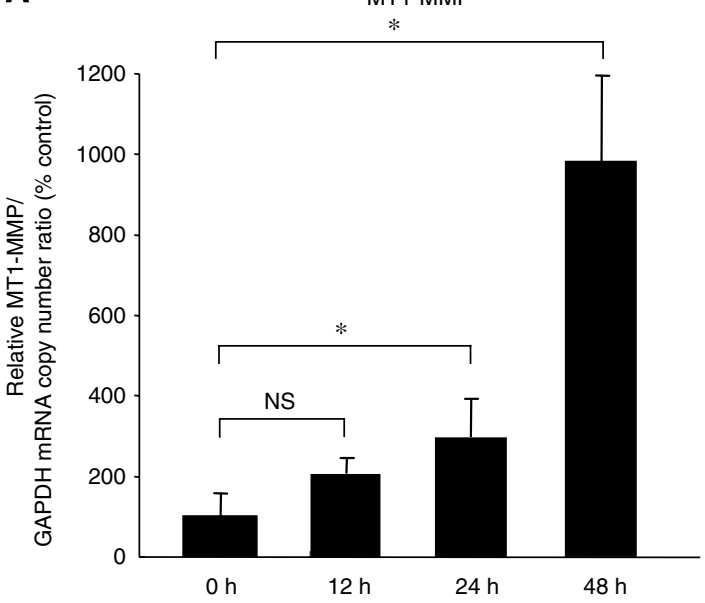

Time after FGF10 (100 $\left.\mathrm{ng} \mathrm{ml}^{-1}\right)$ stimulation

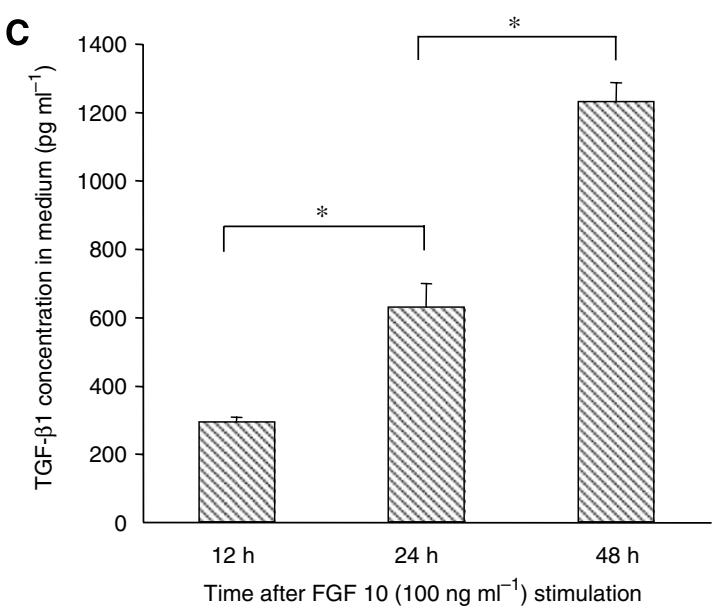

B

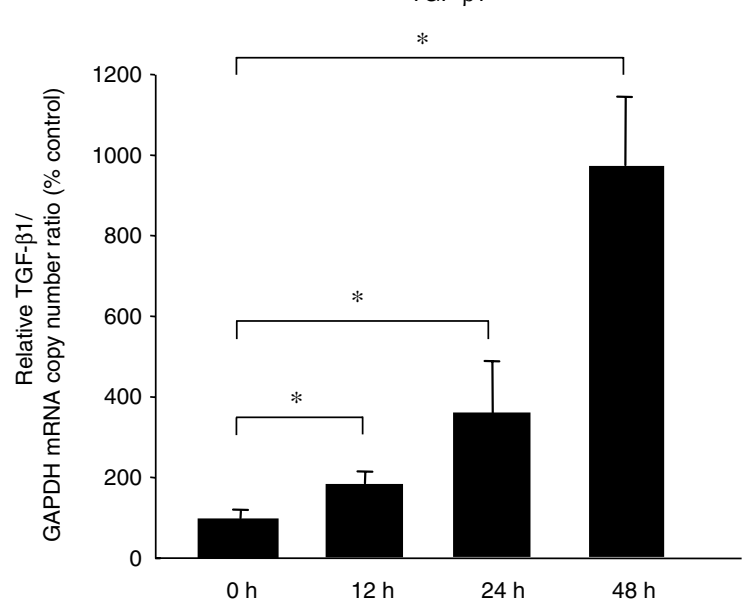

Time after FGF10 (100 $\left.\mathrm{ng} \mathrm{ml}^{-1}\right)$ stimulation

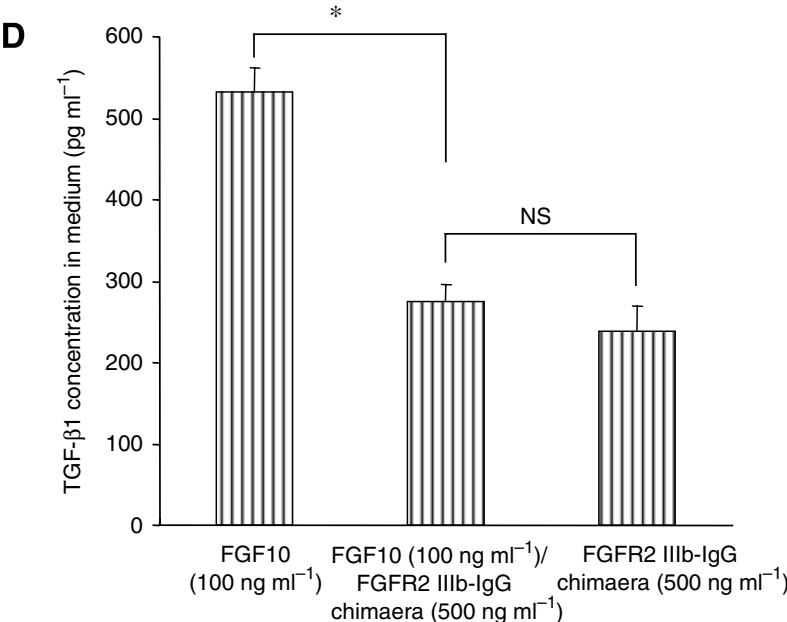

Figure 4 Fibroblast growth factor 10 induces expression of mRNA for MTI-MMP and TGF- $\beta$ I in CFPAC-I cells. The figure shows the relative copy numbers of MTI-MMP (A) and TGF- $\beta$ I (B) mRNA in CFPAC-I cells cultured with $100 \mathrm{ng} \mathrm{ml}^{-1}$ of FGFIO for the indicated times. The MTI-MMP and TGF $\beta I$ mRNA/GAPDH mRNA copy number ratios are shown relative to those of cells without FGFIO stimulation ( $0 \mathrm{~h}$ ). The concentration of TGF- $\beta$ I protein in medium also increased in time-dependent manner in CFPAC-I cells $48 \mathrm{~h}$ after addition of FGFI0 (I00 ng ml $\left.\left.\right|^{-1}\right)(\mathbf{C})$. FGF receptor-2-lllb/lgG chimera $\left(500 \mathrm{ng} \mathrm{ml}^{-1}\right)$ inhibited this TGF- $\beta$ | secretion by FGF I0, whereas chimera alone did not affect TGF- $\beta$ | secretion by itself (D). *P $<0.05$; NS=not significant.

immunostaining of 76 resected pancreatic cancer tissues, and moreover, showed that the expression level of FGFR2-IIIb is correlated with prognosis and the incidence of nodal involvement. These findings indicate that signalling through FGFR2-IIIb may induce malignant potential, and especially, may increase the metastatic ability of pancreatic cancer cells.

FGFR2-IIIb was first identified as a high-affinity receptor of FGF7 (keratinocyte growth factor) (Miki et al, 1992), and it can also be activated by FGF10, which has strong sequence homology with FGF7 (Igarashi et al, 1998). Our results show that FGF10 is expressed in stromal cells scattered around pancreatic cancer cells, suggesting a possible interaction with cancer cells expressing FGFR2-IIIb. To our knowledge, this is the first report of the expression pattern of FGF10 in pancreatic cancer. We also show that FGF10-positive cells and CD3-positive T cells exist in a similar location and have a similar shape. According to these data, we hypothesize that FGF10 is expressed in T cells surrounding pancreatic cancer cells. Supporting this, during wound healing, $\mathrm{T}$ cells bearing $\gamma \delta$ T cell receptors are an important source of FGF7 and FGF10, which activate epithelial cell proliferation (Jameson et al, 2002). Further studies are required for confirming this hypothesis.

Despite the high homology, the function of FGF10 differs slightly from that of FGF7. We found that FGF10 induced cell migration and invasion in pancreatic cancer cells, but had no effect on cell proliferation. Alderson et al (2002) also found that FGF10 does not affect cell proliferation in several types of cancer cells, whereas Niu et al (2007) recently showed that FGF7 stimulates cell proliferation, in addition to cell migration and invasion, in pancreatic ductal epithelial cells. These two genes also have different expression patterns in pancreatic cancer. Cho et al (2007) showed that FGF7 is expressed in pancreatic cancer cells themselves and acts in an autocrine manner, whereas our results showed FGF10 expression in stromal cells of pancreatic cancer, indicating a paracrine FGF10/ FGFR2-IIIb interaction. Further studies are required to understand how these ligands, which share the same receptor on cancer cells, are orchestrated to induce malignant properties in pancreatic cancer. 
To understand how FGF10/FGFR2-IIIb signalling induces cell migration and invasion of pancreatic cancer cells, we examined whether FGF10 influences the expression of genes related to cell mobility. Interestingly, FGF10 induced expression of membrane type 1-matrix metalloproteinase (MT1-MMP) and transforming growth factor (TGF)- $\beta 1 \mathrm{mRNA}$ in CFPAC- 1 cells, and these genes may lead, at least in part, to cell migration and invasion of cancer cells. The metalloproteinases are known to involve cell invasion ability. Within several types of metalloproteinases and their inhibitor that we examined (MMP-1, 2, 7, 9, MT1-MMP, TIMP-2), only the mRNA expression of MT1-MMP was upregulated by FGF10 in CFPAC-1 cells. Membrane type 1-matrix metalloproteinase was originally found as a metalloproteinase with a transmembrane domain in homology screening for the MMP conserved domain (Sato et al, 1994). The MT1-MMP protein induces invasive activity by degrading extracellular matrix surrounding epithelial cells through its proteinase activity, or by activating other proteinases (Seiki, 2003). In pancreatic cancer, enhanced MT1-MMP expression is particularly observed in metastatic lesions (Maatta et al, 2000). These facts may indicate that induction of MT1-MMP is one of the mechanisms through which FGF10 induces cell invasion activity. We are trying to examine if the proteinase activity of MT1-MMP is increased by FGF10 stimulation in pancreatic cancer cells.

TGF- $\beta 1$ is also an important regulator of cell invasion and migration activity, and is frequently overexpressed in pancreatic cancer, with the expression level associated with an advanced tumour stage and a poor prognosis (Friess et al, 1993a,b).
Moreover, TGF- $\beta 1$ is an important regulator of the epithelial mesenchymal transition, in which epithelial cells disassemble their junctional structures, start expressing mesenchymal cell proteins, remodel the extracellular matrix, and become migratory (Moustakas and Heldin, 2007). As a result, cancer cells acquire metastatic properties (Oft et al, 1998; McEarchern et al, 2001), suggesting that FGF10/FGFR2-IIIb-signalling may promote migration of pancreatic cancer cells through induction of TGF- $\beta 1$ expression. We also found that FGF10 induced not only mRNA expression of TGF-b1 but also the secretion of this protein through signalling through FGFR2-IIIb in CFPAC-1 cells. This strongly supports the hypothesis and it should be confirmed in future.

In conclusion, our results indicate an important role for the interaction between stromal cells and parenchymal cells mediated by FGF10/FGFR2-IIIb signalling in pancreatic cancer. This suggests that FGF10 and FGFR2-IIIb are promising candidates as target molecules for new therapy against pancreatic cancer, and that therapeutic agents directed against these molecules may improve the prognosis of patients with this disease.

\section{ACKNOWLEDGEMENTS}

This work is partly supported by grants from Ministry of Education, Culture, Science, Sports, and Technology of Japan. We thank Noboru Mitsuhashi MD PhD for comments on this paper.

\section{REFERENCES}

Alderson R, Gohari-Fritsch S, Olsen H, Roschke V, Vance C, Connolly K (2002) In vitro and in vivo effects of repifermin (keratinocyte growth factor-2, KGF-2) on human carcinoma cells. Cancer Chemother Pharmacol 50: $202-212$

Bhushan A, Itoh N, Kato S, Thiery JP, Czernichow P, Bellusci S, Scharfmann $\mathrm{R}$ (2001) Fgf10 is essential for maintaining the proliferative capacity of epithelial progenitor cells during early pancreatic organogenesis. Development 128: $5109-5117$

Cho K, Ishiwata T, Uchida E, Nakazawa N, Korc M, Naito Z, Tajiri T (2007) Enhanced expression of keratinocyte growth factor and its receptor correlates with venous invasion in pancreatic cancer. Am J Pathol 170: $1964-1974$

Friess H, Yamanaka Y, Buchler M, Berger HG, Kobrin MS, Baldwin RL, Korc M (1993a) Enhanced expression of the type II transforming growth factor $\beta$ receptor in human pancreatic cancer cells without alteration of type III receptor expression. Cancer Res 53: 2704-2707

Friess H, Yamanaka Y, Buchler M, Ebert M, Berger HG, Gold LI, Korc M (1993b) Enhanced expression of transforming growth factor $\beta$ isoforms in pancreatic cancer correlate with decreased survival. Gastroenterology 105: $1846-1856$

Ghaneh P, Costello E, Neoptolemos JP (2007) Biology and management of pancreatic cancer. Gut 56: $1134-1152$

Ghaneh P, Smith R, Tudor-Smith C, Raraty M, Neoptplemos JP (2008) Neoadjuvant and adjuvant strategies for pancreatic cancer. Eur J Surg Oncol 34: $297-305$

Golosow N, Grostein C (1962) Epitheliomesenchymal interaction in pancreatic morphogenesis. Dev Biol 4: 242-255

Ide T, Kitajima Y, Miyoshi A, Ohtsuka T, Mitsuno M, Ohtaka K, Koga Y, Miyazaki K (2006) Tumor-stromal interaction under hypoxia increases the invasiveness of pancreatic cancer cells through the hepatocyte growth factor/c-Met pathway. Int J Cancer 119: 2750-2759

Igarashi M, Finch PW, Aaronson SA (1998) Characterization of recombinant human fibroblast growth factor (FGF)-10 reveals functional similarities with keratinocyte growth factor (FGF-7). J Biol Chem 273: $13230-13235$

Ishiwata T, Friess H, Buchler MW, Lopez ME, Korc M (1998) Characterization of keratinocyte growth factor and receptor expression in human pancreatic cancer. Am J Pathol 153: 213-222
Ishiwata T, Naito Z, Lu YP, Kawahara K, Fujii T, Kawamoto Y, Teduka K, Sugisaki Y (2002) Differential distribution of fibroblast growth factor (FGF)-7 and FGF-10 in L-arginine-induced acute pancreatitis. Exp Mol Pathol 73: $181-190$

Jacquemin P, Yoshitomi H, Kashima Y, Rousseau GG, Lemaigre FP, Zaret KS (2006) An endothelial-mesenchymal relay pathway regulates early phases of pancreas development. Dev Biol 290: 189-199

Jameson J, Ugarte K, Chen N, Yachi P, Fuchs E, Boismenu R, Havran WL (2002) A role for skin $\gamma \delta$ T cells in wound repair. Science 296: $747-749$

Jung J, Zheng M, Goldfarb M, Zaret KS (1999) Initiation of mammalian liver development from endoderm by fibroblast growth factors. Science 284: $1998-2003$

Kalluri R, Zeisberg M (2006) Fibroblasts in cancer. Nat Rev Cancer 6: $392-401$

Koshiba K, Hosotani R, Miyamoto Y, Ida J, Tsuji S, Nakajima S, Kawaguchi M, Kobayashi H, Doi R, Hori T, Fujii N, Imamura M (2000) Expression of stromal cell-derived factor 1 and CXCR4 ligand receptor system in pancreatic cancer: a possible role for tumor progression. Clin Cancer Res 6: $3530-3535$

Li D, Xie K, Wolff R, Abbruzzese JL (2004) Pancreatic cancer. Lancet 363: $1049-1057$

Lin EY, Nguyen AV, Russell RG, Pollard JW (2001) Colony-stimulating factor 1 promotes progression of mammary tumors to malignancy. J Exp Med 193: $727-739$

Maatta M, Soini Y, Liakka A, Autio-Harmainen H (2000) Differential expression of matrix metalloproteinase (MMP)-2, MMP-9, and membrane type 1-MMP in hepatocellular and pancreatic adenocarcinoma: implications for tumor progression and clinical prognosis. Clin Cancer Res 6: $2726-2734$

Marchesi F, Monti P, Leone BE, Zerbi A, Vecchi A, Piemonti L, Mantovani A, Allavena P (2004) Increased survival, proliferation, and migration in metastatic human pancreatic tumor cells expressing functional CXCR4. Cancer Res 64: 8420-8427

McEarchern JA, Kobie JJ, Mack V, Wu RS, Meade-Tollin L, Arteaga CL, Dumont N, Besselsen D, Sefter E, Hendrix MJ-C, Katsanis E, Akporiaye ET (2001) Invasion and metastasis of a mammary tumor involves TGF- $\beta$ signaling. Int J Cancer 91: 76-82 
Miki T, Bottaro DP, Fleming TP, Smith CL, Burgess WH, Chan AM.-L, Aaronson SA (1992) Determination of ligand-binding specificity by alternative splicing: two distinct growth factor receptors encoded by a single gene. Proc Natl Acad Sci USA 89: 246-250

Mitsuhashi N, Shimizu H, Ohtsuka M, Wakabayashi Y, Ito H, Kimura F, Yoshidome H, Kato A, Nukui Y, Miyazaki M (2003) Angiopoietins and Tie-2 expression in angiogenesis and proliferation of human hepatocellular carcinoma. Hepatology 37: 1105-1113

Moustakas A, Heldin CH (2007) Signaling networks guiding epithelialmesenchymal transitions during embryogenesis and cancer progression. Cancer Sci 98: 1512 - 1520

Niu J, Chang Z, Peng B, Xia Q, Lu W, Huang P, Tsao MS, Chiao PJ (2007) Keratinocyte growth factor/fibroblast growth factor-7-regulated cell migration and invasion through activation of NF- $\mathrm{KB}$ transcription factors. J Biol Chem 282: $6001-6011$

Oft $M$, Heider KH, Beug $H$ (1998) TGF- $\beta$ signaling is necessary for carcinoma cell invasiveness and metastasis. Curr Biol 8: 1243-1252

Orimo A, Gupta PB, Sgroi DC, Arenzana-Seisdedos F, Delaunay T, Naeem R, Carey VJ, Richardson AL, Weinberg RA (2005) Stromal fibroblasts present in invasive human breast carcinomas promote tumor growth and angiogenesis through elevated SDF-1/CXCL12 secretion. Cell 121: $335-348$

Pollard JW (2004) Tumour-educated macrophages promote tumour progression and metastasis. Nat Rev Cancer 4: 71-78

Pulkkinen MA, Spencer-Dene B, Dickson C, Otonkoski T (2003) The IIIb isoform of fibroblast growth factor receptor 2 is required for proper growth and branching of pancreas ductal epithlium but not for differentiation of exocrine or endocrine cells. Mech Dev 120: 167-175

Sato H, Takino T, Okada Y, Cao J, Shinagawa A, Yamamoto E, Seiki M (1994) A matrix metalloproteinase expressed on the surface of invasive tumour cells. Nature 370: $61-65$

Seiki M (2003) Membrane-type 1 matrix metalloproteinase: a key enzyme for tumor invasion. Cancer Lett 194: 1-11

Willett CG, Czito WB, Bendell JC, Ryan DP (2005) Locally advanced pancreatic cancer. J Clin Oncol 20: 4538-4544

Yoshitomi H, Zaret KS (2003) Endothelial cell interactions intiate dorsal pancreas development by selectively inducing the transcription factor Ptfla. Development 131: 807-817 